\title{
FATALITIES IN ROAD TRAFFIC; A RESULT OF ACCIDENTS OR SUICIDES
}

Anna-Lena Andersson, $\mathrm{PhD}$, Special Adviser Traffic Safety

Swedish Transport Administration / Institute of Clinical Sciences at Sahlgrenska Academy, University of Gothenburg, Department of Orthopedics

Swedish Transport Administration, SE-405 33 Gothenburg, Sweden

Phone: + 467056093 22,

E-mail: anna-lena.andersson@trafikverket.se

Co-author; Kenneth Svensson, Special Adviser Traffic Safety, Swedish Transport Administration. 


\section{INTRODUCTION}

Most fatalities in road traffic are accidents, but some are suicides. The Swedish Parliament decided in 2010 to identify suicides in road traffic and separate them from fatalities caused by accidents. To undertake this task a method has been developed for classification of road traffic fatalities in order to determine if the fatality was caused by accident or suicide. It can be difficult to assess whether a fatality is due to one or the other. Reporting statistics about suicides is a difficult task as the hidden cases are to be aware of.

Vision Zero is the Swedish ethical standpoint against road accidents and it is based on the idea that any loss of life in traffic is unacceptable. No-one should be killed or permanently disabled because of road traffic.

In-depth studies are made for all road fatalities in Sweden, since 1997 by investigators at the Swedish Transport Administration (STA). In each case information of the vehicle, the road and event, and the road user are collected.

\section{AIM}

The aim of this study was to assess the number of road traffic suicides by studying fatality from three angles; the vehicle, the road and the road user. The main focus was to devise and undertake a psychosocial examination of the road user.

\section{METHOD}

In 2012, 322 people were killed in Swedish traffic. In 49 cases the in-depth study investigators suspected that the fatalities were due to suicides.

The criteria for cases to undergo the psychosocial investigations were if there was a farewell message; oral or written. If the traffic event was suspected in combination with psychosocial knowledge, such as recent known suicide attempts, resent indirect or direct suicidal communication, ongoing depression or mental illness or previous severe stressful live event. Another criteria was a traffic event that strongly indicated a suicide.

A classification scale was used and had five levels, where level one and two were classified as suicides, when the result of the examination showed...

1. that the manner of death was suicide

2. strongly supported that the manner of death was suicide

3. could not determine whether the manner of death was suicide or the result of an accident

4. strongly supported that the manner of death was a result of an accident

5. showed that the manner of death was an accident

In the 49 cases the in-depth study investigators suspected that the fatality was due to suicide, they reported these to the psychosocial investigator. The study was conducted by the special investigator in behavioural science with experience from counselling at hospitals. An expanded psychosocial data collection was done in each of these cases. This was done by material from the in-depth study, through contact with the police and sometimes with the relatives, as well as by studying the autopsy report, when an autopsy had been carried out. Sometimes health care records from earlier medical treatment were used, when available. 
The 49 suspected suicides were classified by an expert group of five experienced professionals with knowledge in forensic medicine, psychology, behavioral science and traffic safety using the classification system. Two classifications were made. Firstly classification was made without information from the psychosocial examination. Hereafter classification was performed with the additional psychosocial information.

\section{RESULTS}

Table 1. Results before and after psychosocial examination year 2012

\begin{tabular}{|c|c|c|c|c|}
\hline & The manner of death & Before & After & \\
\hline 1 & Showed ... suicide & 10 & $\overline{14}$ & \\
\hline 2 & Stronoly sunnorted suicide & 12 & 20 & $11 \%$ \\
\hline 3 & Could not be determined $\ldots$ suicide or the result of an accident & 20 & 8 & \\
\hline 4 & Strongly supported... accident & 7 & 5 & \\
\hline \multirow[t]{2}{*}{5} & Showed... accident & 224 & 224 & \\
\hline & Total & 273 & 273 & \\
\hline
\end{tabular}

Twenty-two or $7 \%$ were classified as suicides without the psychosocial information and thirty-six or $11 \%$ with all information included. The uncertain cases were reduced from 20 to 8 .

\section{DISCUSSION}

A traffic road fatality should be investigated from different angles; the road environment, the vehicle, the traffic event and by data about the psychosocial history and private situation before the crash. Human factors are very important, and often explain what happened. Ordinary road user data like gender, age, influence of alcohol etc. are not enough. They should be complemented by a more comprehensive psychosocial investigation to find the explanation of the manner of death. A limitation of the study is the relatively small number of cases, but after the first year with the cooperation with the in-depth study investigators and with the police, the data from them started to get better quality. Therefore another year of collected cases had not been comparable with the data from 2012. Therefor the method was implemented in ordinary work from 2013. With the psychosocial investigations in ordinary suicide classification the uncertain cases can be reduced. The analysis of the basis, for example object of collisions or road environment where pedestrians' suicides take place, should be considered in connection with reconstruction or construction of road environment.

\section{CONCLUSION}

Identifying suicides in road traffic demands a holistic view of human factors, when collecting data. The psychosocial history of the deceased in combination with the traffic event and data about the road and vehicle, as well as information from the police and from the autopsy report are needed for high quality of suicide classification. A well formulated structure of the method is necessary and a consistent 
working ship in the expert group is demanded. The mix of knowledge in forensic medicine, psychology, behavioral science and traffic safety has proven successful.

\section{FUTURE}

There are other modes of suicide methods where the intention is difficult to identify, such as in the railway transport system, falls from heights, fatal fires and intoxications. This method can be modified to suit other methods. The circumstances of the event have to be investigated and the psychosocial and human factors are relevant objects to study in suicide classification.

\section{SUMMARY}

Introduction: Not all fatalities in road traffic are accidents, some are suicides. Sweden presents accidents separate from accident in road traffic since 2010.

Aim: To assess if the number of uncertain cases could be reduced by psychosocial investigations.

Method: In 2012, 322 people were killed in Swedish traffic. In 49 cases the in-depth investigators at the Swedish Transport Administration suspected that the fatality was due to suicide. The psychosocial investigator conducted an expanded psychosocial data collection by material from the in-depth study, through contact with the police and sometimes with relatives, as well as by studying the autopsy report, when an autopsy had been carried out. In some cases the health care records from earlier medical treatment were available. The classification method contained criteria for cases to undergo a psychosocial investigation and a classification model with five levels, where cases classed as level one or two were classified as suicides.

Results: Twenty-two or $7 \%$ were classified as suicides without the psychosocial information and thirtysix or $11 \%$ with all information included. The uncertain cases were reduced from 20 to 8 .

Discussion: A traffic road fatality should be investigated from different angles; the road environment, the vehicle, the traffic event and by data about the psychosocial history and private situation before the crash. Human factors are very important, and often explain what happened.

Conclusion: Identifying suicides in road traffic demands a holistic view of human factors and psychosocial information when collecting data. A well formulated structure of the method is necessary and a consistent working ship in the expert group is demanded. The mix of knowledge in forensic medicine, psychology, behavioral science and traffic safety has proven successful.

\section{REFERENCES}

Swedish Road Administration (2014). Vilka dödsfall i vägtrafiken är suicid? Metodbeskrivning samt analys av åren 2010-2013. Publication 2014:113.

Fatalities in road traffic; a result of accident or suicide. In manuscript. 